\title{
Corpo, mENTE E CÉREBro NA ANTIGUidAdE: UM BREVE ESTUDO HISTÓRICO
}

\author{
Fabiano dos Santos Castro
}

Atualmente, o debate sobre a natureza da mente humana vem tomando novos rumos graças ao desenvolvimento de diversos estudos, no campo da neurociência, que investigam a localização das funções cerebrais. Entretanto, este conhecimento acumulado não ocorreu de forma súbita. O presente trabalho investiga as principais observações sobre a relação entre as diversas estruturas do corpo (tais como o cérebro ou o coração) e as atividades mentais nas primeiras civilizações antigas.

\section{BANCA:}

Jesus Landeira Fernandez (Orientador)

Ana Maria Jacó-Vilela

Isabela Fernandes Soares Leite

Data da defesa: 16/02/2009 